\title{
EFEKTIVITAS MODEL JIGSAW DISERTAI PENILAIAN DISKUSI UNTUK MENINGKATKAN KEMAMPUAN MATEMATIS MAHASISWA
}

\author{
Sofia Edriati, Villia Anggraini, dan Mery Siska \\ STKIP PGRI Sumatera Barat \\ email: sofia.edriati@yahoo.co.id
}

\begin{abstract}
Abstrak: Penelitian ini bertujuan untuk mengetahui perbedaan peningkatan kemampuan matematis mahasiswa yang menggunakan model jigsaw disertai penilaian diskusi dengan tanpa penilaian diskusi dan perkuliahan konvensional. Penelitian ini menggunakan metode true eksperiment dengan randomized control-group pretest-posttest design. Populasi penelitian adalah mahasiswa yang mengambil mata kuliah Aljabar Linier Elementer. Sampel sebanyak tiga kelas dipilih secara cluster random sampling. Data yang diperoleh dengan teknik tes (awal dan akhir), sedang analisis data dilakukan dengan menggunakan skor gain rata-rata. Sebelum data dianalisis terlebih dahulu dilakukan uji persyaratan, yaitu berupa uji normalitas, homogenitas, dan kesamaan kompeetnsi awal. Hasil penelitian menunjukkan bahwa terdapat perbedaan peningkatan kemampuan matematis mahasiswa yang menggunakan model jigsaw disertai penilaian diskusi dengan tanpa penilaian diskusi dan perkuliahan konvensional.
\end{abstract}

Kata Kunci: penilaian diskusi, model jigsaw, kemampuan matematis

\section{THE EFFECTIVENESS OF JIGSAW MODELS WITH ASSESSMENT OF DISCUSSION TO IMPROVE MATHEMATICAL ABILITY OF STUDENT}

\begin{abstract}
This research aims to determine of differences in improvement of student mathematical ability who use the jigsaw model accompanied with discussion assessment to without discussion assessment and conventional learning. The research method used true approach experiment with randomized control-group pretest-posttest design. The study population were students who take courses Elementary Linear Algebra. The data obtained were analyzed by using gain score. The results showed that there are differences in improvement of student mathematical ability who use the jigsaw model with discussion assessment to without discussion assessment and conventional learning.
\end{abstract}

Keywords: discussion assessment, jigsaw model, mathemathical ability

\section{PENDAHULUAN}

Keberhasilan akademik dan profesional mahasiswa program studi pendidikan matematika sangat difasilitasi oleh tingkat kemampuan matematis masing-masing. Untuk mampu memecahkan masalah, mahasiswa harus memahami konsep-konsep matematika yang terkait. Mahasiswa akan mudah dalam bernalar dan mengkomunikasikan ide atau gagasan matematis apabila bisa memahami konsep dengan baik. Kemampuan matematis ini dapat ditingkatkan dalam proses perkuliahan yang memfasilitasi aktivitas intelektual mahasiswa seperti diskusi dan komunikasi.

Model pembelajaran langsung yang biasa digunakan dalam perkuliahan belum bisa memaksimalkan aktivitas diskusi dan komunikasi mahasiswa. Kecendrungan mahasiswa hanya menyimak dengan sedikit interaksi antarmahasiswa dan dosen. Kebiasaan belajar yang hanya menunggu dan mengharapkan sepenuhnya penjelasan materi dari dosen belum cukup efektif dalam meningkatkan pemahaman mahasiswa terhadap materi ajar. Keterlibatan mahasiswa yang sangat kurang dalam proses pembelajaran tidak dapat memfasilitasi mahasiswa untuk berpikir kritis dan informasi yang diberikan mungkin tidak bertahan lama. Wijaya (2012:130) menemukan bahwa keterlibatan dan keaktifan siswa dalam mengikuti proses diskusi berpengaruh positif terhadap kinerja akademik mahasiswa. Oleh karena itu, dosen perlu memilih model pembelajaran yang sesuai dan dapat memfasilitasi aktivitas diskusi mahasiswa. 
Salah satu model pembelajaran yang dapat memfasilitasi aktivitas diskusi dan komunikasi mahasiswa adalah model pembelajaran kooperatif tipe jigsaw. Model pembelajaran ini lebih menekankan pada keaktifan mahasiswa dalam proses perkuliahan. Mahasiswa diharapkan berperan aktif dalam memperoleh pengetahuan.

Model pembelajaran kooperatif tipe jigsaw adalah sebuah model belajar kooperatif yang menitikberatkan pada kerja mahasiswa dalam bentuk kelompok kecil yang harus saling membantu (Sharan, 2012:55). Mahasiswa bekerja sama saling ketergantungan dalam kelompok heterogen yang terdiri atas lima atau enam orang anggota. Mahasiswa dengan topik yang sama dari kelompok yang berbeda bergabung dalam kelompok ahli, saling membantu dalam memahami topik mereka. Setelah itu, mahasiswa kembali ke kelompok asal dan mengajarkan apa yang sudah dipelajari kepada anggota kelompoknya (Arends, 2012:368).

Menurut penelitian Nurhaeni (2011: 88), penggunaan model jigsaw dalam pembelajaran dapat meningkatkan pemahaman siswa terhadap materi pelajaran. Hal ini juga didukung oleh Fries (2008:87) yang menyatakan bahwa model jigsaw dapat mengaktifkan peserta didik dan berkolaborasi dalam memahami materi pelajaran. Penelitian yang dilakukan oleh Naomi dan Githua (2013:186) juga menemukan bahwa peserta didik yang menggunakan model jigsaw memberikan hasil yang lebih baik daripada yang menggunakan metode konvensional.

Suatu bentuk penilaian dapat dilakukan untuk memotivasi mahasiswa dalam melaksanakan diskusi secara efektif selama proses perkuliahan berlangsung. Boud dan Falchikov menyatakan bahwa penilaian adalah pendorong fundamental belajar peserta didik (McNamara \& Burton, 2009:2).

Penilaian dapat disesuaikan dengan aktivitas yang dilakukan mahasiswa seperti diskusi kelompok. Vonderwell, Liang, dan Alderman (2007) menemukan bahwa forum diskusi sangat penting untuk keberhasilan pembelajaran dan penilaian (McNamara \& Burton, 2009:3). Penilaian diskusi merupakan salah satu penilaian proses yang memungkinkan dilakukan pengukuran secara langsung yang menuntut mahasiswa untuk berunjuk kerja dalam situasi yang konkret dan bermakna sekaligus mencerminkan penguasaan mahasiswa terhadap materi pembelajaran (Nurgiyantoro, 2008: 254).

Penilaian diskusi difokuskan pada aspek partisipasi, kontribusi, saling menghargai dan percaya diri selama kegiatan diskusi berlangsung. Penilaian dilakukan terhadap keempat aspek tersebut untuk melihat keterlibatan mahasiswa dalam diskusi kelompok yang dilaksanakan sesuai dengan sintak pembelajaran kooperatif tipe Jigsaw.

Penelitian ini bertujuan untuk mengetahui perbedaan peningkatan kemampuan matematis mahasiswa yang menggunakan model jigsaw disertai penilaian diskusi dengan tanpa penilaian diskusi dan perkuliahan konvensional yang dipengaruhi peran dosen. Di samping itu, penelitian ini juga bertujuan untuk mengetahui apakah kemampuan matematis mahasiswa yang menggunakan model jigsaw disertai penilaian diskusi lebih baik daripada tanpa penilaian diskusi dan perkuliahan konvensional.

Penelitian ini diharapkan dapat bermanfaat bagi para dosen sebagai alternatif model perkuliahan dan evaluasi proses perkuliahan. Penilaian diskusi yang digunakan juga dapat dijadikan sebagai salah satu cara untuk membangkitkan motivasi dan antusiasme mahasiswa dalam mengikuti perkuliahan. Selain itu, dapat dijadikan sebagai pertimbangan dalam peningkatan mutu perkuliahan yang lebih tepat sasaran sehingga dapat meningkatkan prestasi belajar mahasiswa.

\section{METODE}

Penelitian ini merupakan penelitian true eksperiment dengan rancangan Randomized Control-Group Pretest-Posttest Design. Sesuai dengan permasalahan penelitian, rancangan ini diperluas untuk dua variabel bebas seperti disajikan pada Tabel 1.

Populasi penelitian ini adalah mahasiswa Program Studi Pendidikan Matematika yang mengambil mata kuliah Aljabar Linier Elementer semester ganjil tahun pelajaran 2013/2014 di 
Tabel 1. Rancangan Penelitian

\begin{tabular}{lccc}
\hline Kelas Sampel & $\begin{array}{c}\text { Tes } \\
\text { Awal }\end{array}$ & Perlakuan & $\begin{array}{c}\text { Tes } \\
\text { Akhir }\end{array}$ \\
\hline Eksperimen 1 & $\mathrm{T}_{1}$ & $\mathrm{X}_{\mathrm{a}}$ & $\mathrm{T}_{2}$ \\
Eksperimen 2 & $\mathrm{T}_{1}$ & $\mathrm{X}_{\mathrm{b}}$ & $\mathrm{T}_{2}$ \\
Kontrol & $\mathrm{T}_{1}$ & & $\mathrm{~T}_{2}$ \\
\hline
\end{tabular}

Sumber: Suryabrata (2004: 106)

Keterangan:

$\mathrm{X}_{\mathrm{a}} \quad$ : Pembelajaran model jigsaw dengan penilaian diskusi

$\mathrm{X}_{\mathrm{b}} \quad$ : Pembelajaran model jigsaw tanpa penilaian diskusi

salah satu perguruan tinggi swasta di kota Padang. Berdasarkan hasil uji normalitas dan homogenitas variansi terhadap data indeks prestasi kumulatif (IPK) populasi, diketahui bahwa data berdistribusi normal dan memiliki variansi yang homogen, sehingga pengujian kesamaan rata-rata IPK dapat dilakukan dengan menggunakan analisis variansi.

Hasil pengujian kesamaan rata-rata yang dilakukan secara statistik, menunjukkan bahwa data IPK populasi memenuhi asumsi kesamaan rata-rata sehingga subjek dapat dimasukkan secara acak ke dalam sampel penelitian. Jadi, sampel pada penelitian ini terdiri atas dua kelas eksperimen dan satu kelas kontrol yang dipilih secara cluster random sampling.
Instrumen yang digunakan dalam penelitian ini adalah lembar observasi kegiatan diskusi, soal tes awal dan soal tes akhir yang berbentuk uraian. Teknik analisis data hasil tes awal dan tes akhir menggunakan skor gain ratarata, yaitu:

$$
g=\frac{\text { skor }_{\text {tes akhir }}-\text { skor }_{\text {tes awal }}}{\text { skor }_{\text {ideal }}-\text { skor }_{\text {tes awal }}}
$$

Peningkatan hasil tes dikategorikan rendah apabila $g<0,3$, termasuk kategori sedang apabila $0,3 \leq g \leq 0,7$, termasuk kategori tinggi apabila $g>0,7$.

\section{HASIL DAN PEMBAHASAN}

Hasil analisis data tes awal dan tes akhir menunjukkan bahwa terjadi peningkatan kemampuan matematis mahasiswa pada ketiga kelas sampel. Perolehan skor rata-rata gain $(g)$ kemampuan matematis kelas eksperimen 1 adalah 0,57 , skor rata-rata gain pada kelas eksperimen 2 adalah 0,50 , dan pada kelas kontrol diperoleh skor 0,30 . Perolehan skor rata-rata gain $(g)$ kemampuan matematis ketiga kelas sampel termasuk kategori sedang. Rata-rata nilai tes awal, tes akhir, dan gain kemampuan matematis mahasiswa ketiga kelas sampel disajikan pada Gambar 1.

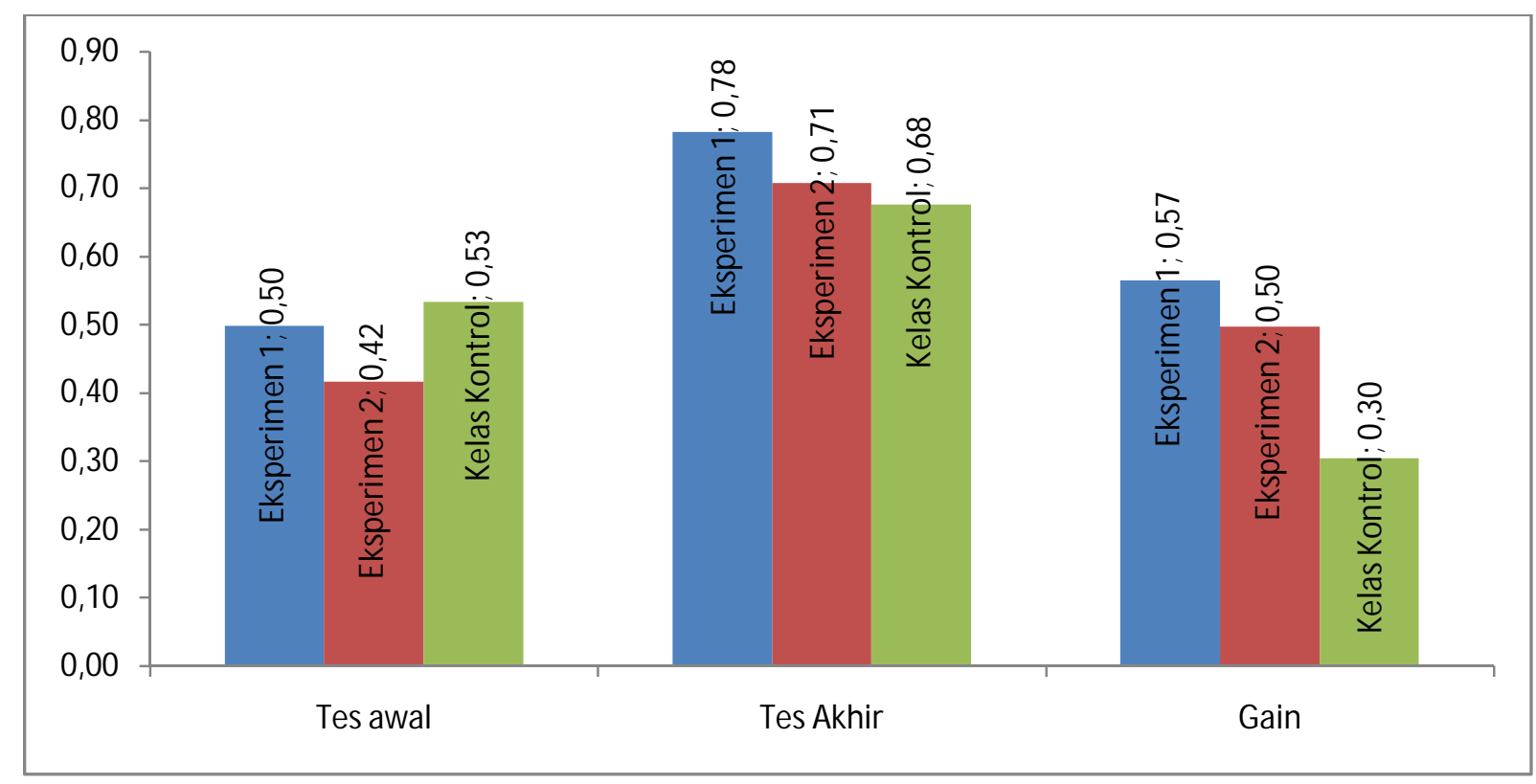

Gambar 1. Skor Rata-rata Tes Awal, Tes Akhir, dan Gain Kemampuan Matematis Siswa Kelas Sampel 
Grafik gain pada Gambar 1 memperlihatkan ketinggian yang berbeda pada pada ketiga kelas sampel. Grafik paling tinggi ditemukan pada kelas eksperimen 1. Hal ini menunjukkan bahwa terdapat perbedaan peningkatan kemampuan matematis mahasiswa pada ketiga kelas sampel meskipun skor peningkatan (rata-rata gain) ketiganya berada pada kriteria yang sama.

Rata-rata peningkatan kemampuan matematis di kelas eksperimen 1 berbeda sebesar $14 \%$ dengan kelas eksperimen 2 . Hal ini disebabkan penilaian diskusi di kelas eksperimen 1 mendorong mahasiswa untuk belajar sehingga memberikan dampak positif terhadap pencapaian akademik mahasiswa (Wijaya, 2012:130).

Berdasarkan hasil pengamatan selama penelitian berlangsung, ditemukan bahwa mahasiswa di kelas eksperimen 1 lebih aktif dalam melakukan diskusi di kelompok ahli maupun di kelompok asal. Sedangkan di kelas eksperimen 2 , hanya beberapa mahasiswa yang terlihat aktif dalam diskusi di kelompok ahli. Mahasiswa cenderung hanya bertukar catatan dalam diskusi di kelompok asal.

Weaver dan Qi (Wijaya, 2012:130) menyatakan bahwa mahasiswa yang aktif dalam proses diskusi akan belajar lebih banyak daripada mahasiswa yang tidak berpartisipasi aktif. Dengan demikian, diduga perbedaan kemampuan matematis antara kelas eksperimen 1 dan eksperimen 2 disebabkan oleh keaktifan mahasiswa dalam berdiskusi berbeda pada kedua kelas eksperimen tersebut. Penilaian diskusi yang dilakukan di kelas eksperimen 1 cukup memotivasi mahasiswa untuk berpartisipasi dan berkontribusi secara aktif.

Skor peningkatan kemampuan matematis pada kelas kontrol sebesar 0,3 berada pada batas bawah kriteria sedang (sangat dekat dengan kriteria rendah). Hal ini disebabkan oleh model pembelajaran yang digunakan pada kelas kontrol, yaitu model pembelajaran langsung. Model ini tidak memfasilitasi mahasiswa untuk terlibat aktif dalam pembelajaran.

Enwing (2011:84) mengemukakan bahwa model pembelajaran langsung menghambat keterlibatan aktif mahasiswa dalam memahami matematika dan hanya beberapa mahasiswa yang dapat belajar dengan cara ini. Pada model ini, pengetahuan ditransmisikan ke mahasiswa dengan sedikit interaksi atau bahkan tidak ada diskusi. Dosen sebagai pemilik otoritas pengetahuan dan mahasiswa sebagai penerima pasif. Proses pembelajaran di kelas kontrol didominasi oleh dosen sebagai sumber informasi.

Berdasarkan skor gain pada kelas eksperimen 2 dan kelas kontrol, dapat disimpulkan peningkatan yang terjadi pada kelas eksperimen 2 lebih besar daripada kelas kontrol. Dengan kata lain, model pembelajaran yang digunakan di kelas eksperimen 2 lebih efektif dalam meningkatkan kemampuan matematis mahasiswa daripada metode konvensional yang digunakan di kelas kontrol.

Mahasiswa yang mengikuti perkuliahan model jigsaw disertai penilaian diskusi dan tanpa penilaian diskusi sejak awal sudah dihadapkan dengan tanggung jawab untuk bekerjasama saling ketergantungan dalam memahami materi perkuliahan. Mahasiswa mendiskusikan materi yang sama dalam kelompok ahli sehingga mereka memahami materi dengan baik dan mampu menjadi ahli dalam bidang kajian masing-masing. Kemudian, setiap ahli kembali ke kelompok asal dan dituntut untuk mendemonstrasikan dan berbagi keahlian masing-masing dengan anggota kelompoknya sehingga setiap anggota kelompok asal dapat memahami semua bidang keahlian.

Salah satu temuan pada penelitian ini yaitu kemampuan matematis mahasiswa yang mengikuti perkuliahan model jigsaw dengan penilaian diskusi dan model jigsaw tanpa penilaian diskusi mengalami peningkatan yang cukup signifikan berdasarkan hasil tes awal dan tes akhir. Hasil penelitian ini mendukung penelitian sebelumnya yang dilakukan oleh Saguni (2013:214) yang menemukan bahwa tipe jigsaw dapat meningkatkan prestasi belajar karena mahasiswa bekerjasama dalam kelompok, saling berdiskusi untuk mendalami materi kuliah sehingga mempengaruhi prestasi belajarnya. 
Penerapan model jigsaw dalam perkuliahan menumbuhkan rasa tanggung jawab mahasiswa untuk belajar lebih giat. Mahasiswa yang tergolong pandai dapat memperluas pemahaman dengan menjelaskan materi pada mahasiswa lain. Mahasiswa yang tergolong kurang pandai berusaha lebih keras karena harus mengajarkan materi kepada anggota lainnya. Penerapan model pembelajaran kooperatif tipe Jigsaw dapat meningkatkan kualitas pembelajaran dan melatih keterampilan sosial mahasiswa, kemampuan komunikasi, kerja sama dan meningkatkan rasa tanggung jawab mahasiswa terhadap tugas (Sukarta dan Gunamantha, 2012: 140). Mahasiswa juga dapat belajar dari hasil presentasi kelompok lain dan dari umpan balik yang diberikan dosen (Hsiung, 2012:134).

Darnon, Buchs, dan Desbar (2012:446) menemukan bahwa penerapan pendekatan jigsaw dalam kelas dapat menjadi alat yang efektif untuk meningkatkan kualitas pengalaman belajar mahasiswa. Aktivitas diskusi yang dilakukan dalam kelompok ahli untuk memahami materi bersama, kemudian dilanjutkan dengan berbagi materi yang berbeda dalam kelompok asal dapat meningkatkan pengalaman belajar mahasiswa.

Kegiatan diskusi dan saling berbagi ilmu juga dapat meningkatkan rasa percaya diri mahasiswa dalam mengemukakan pendapatnya kepada forum. Sebagaimana diungkapkan oleh Mengduo dan Xiaoling (2010:119) bahwa sebagian besar peserta didik lebih percaya diri dalam keterampilan interpersonal mereka setelah pembelajaran jigsaw dan 67\% mengakui bahwa diskusi sangat diperlukan. Mengduo dan Xialing (2010:122), juga menyatakan bahwa strategi jigsaw merupakan cara yang tepat untuk meningkatkan partisipasi peserta didik dan antusiasme serta teknik yang berguna untuk fokus dalam menyelesaikan tugas-tugas pembelajaran.

Perbedaan hasil yang diperoleh pada kelompok jigsaw disertai penilaian diskusi dan kelompok jigsaw tanpa penilaian diskusi diperkirakan karena pengaruh penilaian yang dilakukan terhadap aktivitas diskusi setiap mahasiswa. Mahasiswa yang mengikuti perkuliahan model jigsaw disertai penilaian diskusi dihadapkan pada penilaian partisipasi dan kontribusi dalam berdiskusi di kelompok ahli dan kelompok asal. Penilaian diskusi yang dilakukan dapat memotivasi mahasiswa agar berusaha memahami konsep dan belajar mengkomunikasikan konsepkonsep tersebut sehingga mereka bisa turut berpartisipasi. Mahasiswa juga memiliki kepercayaan diri dalam mengemukakan ide dan pendapatnya.

Berdasarkan hasil pengamatan selama penelitian, ditemukan bahwa mahasiswa yang mengikuti perkuliahan menggunakan model jigsaw tanpa penilaian diskusi terlihat sibuk mencatat penjelasan beberapa mahasiswa yang tergolong pandai pada saat diskusi kelompok ahli. Ketika berada dalam kelompok asal, mahasiswa juga sibuk menyalin catatan temannya. Mereka hanya mengandalkan catatan padahal setiap mahasiswa sudah dilengkapi dengan bahan ajar.

Pelaksanaan perkuliahan pada kelas eksperimen 2 yang menggunakan model jigsaw belum terlaksana sebagaimana mestinya. Mahasiswa diharapkan dapat memperluas pemahaman terhadap materi melalui kegiatan diskusi yang dilakukan. Akan tetapi, temuan di atas menunjukkan bahwa pelaksanaan diskusi dalam perkuliahan yang menggunakan model jigsaw membutuhkan keterampilan dosen dalam mengontrol dan mengorganisasikan proses pembelajaran. Sebagaimana dinyatakan oleh Hertiavi, Langlang, dan Khanafiyah (2010:56) bahwa dalam pelaksanaan pembelajaran kooperatif tipe jigsaw, pendidik hendaknya lebih terampil dalam mengorganisasikan peserta didik saat pembentukan kelompok dan diskusi agar waktu untuk pembelajaran lebih efektif.

Pendidik juga perlu lebih menyosialisasikan model pembelajaran kooperatif tipe Jigsaw agar peserta didik tidak kesulitan dalam mengikuti serta mengerjakan tugas-tugasnya dan tidak menghambat proses pembelajaran. Untuk keberhasilan pelaksanaan jigsaw, guru harus terampil menangani participants'requests (misalnya pengelompokan) dan bisa memastikan peserta memiliki pemahaman yang jelas dari setiap langkah metode ini (Chan, 2004: 96). 
Sesuai dengan temuan pada penelitian ini, kemampuan matematis mahasiswa yang mengikuti perkuliahan secara konvensional lebih rendah daripada yang mengikuti perkuliahan menggunakan model jigsaw disertai penilaian diskusi dan tanpa penilaian diskusi. Kondisi ini disebabkan perkuliahan yang dilakukan bersifat pemberian informasi dari dosen kepada mahasiswa sehingga aktivitas mahasiswa didominasi kegiatan mendengar dan mencatat saja.

Berdasarkan hasil pengamatan di kelas kontrol, mahasiswa cukup antusias dalam mengikuti perkuliahan. Mereka mampu merespon setiap kegiatan dan pertanyaan yang diajukan. Hal ini terlihat dari aktivitas yang dilakukan oleh mahasiswa seperti memperhatikan penyampaian materi dari dosen, membaca buku atau bahan ajar yang disediakan. Akan tetapi, aktivitas tersebut belum bisa memfasilitasi mahasiswa dalam membangun pemahaman terhadap materi yang dipelajari. Sesuai dengan yang ditemukan oleh Saguni (2013:214) bahwa metode konvensional kurang mengaktifkan mahasiswa dalam membangun pemahaman terhadap materi yang dipelajari.

Beberapa penelitian sebelumnya juga menemukan bahwa model jigsaw dapat meningkatkan prestasi akademik siswa dan berkontribusi terhadap penghapusan kesalahan konseptual dan kekurangan informasi (Turaçoğlu, Alpat, dan Ellez, 2013:268). Model jigsaw mampu meningkatkan tanggung jawab dan saling ketergantungan dalam kelompok sehingga dapat meningkatkan prestasi belajar mahasiswa sebagaimana dinyatakan oleh Lewis (2012:17) bahwa model pembelajaran kooperatif tipe jigsaw dapat menumbuhkan sikap positif mahasiswa.

Pada perkuliahan yang menerapkan model jigsaw, mahasiswa bisa membangun pemahaman terhadap materi perkuliahan melalui diskusi bersama anggota kelompok, membaca bahan ajar, dan bertanya pada dosen (Denton, 2012:35). Penilaian kegiatan diskusi bisa menjadi salah satu cara bagi dosen dalam memotivasi mahasiswa dan meningkatkan partisipasi serta antusiasme mahasiswa dalam berdiskusi.

\section{PENUTUP}

Berdasarkan hasil penelitian dan pembahasan yang telah dikemukakan, terdapat perbedaan peningkatan kemampuan matematis mahasiswa yang mengikuti perkuliahan menggunakan model jigsaw disertai penilaian diskusi, dengan tanpa penilaian diskusi, dan perkuliahan konvensional. Peningkatan kemampuan matematis mahasiswa yang mengikuti perkuliahan model jigsaw disertai penilaian diskusi lebih tinggi daripada tanpa penilaian diskusi dan perkuliahan konvensional.

Berdasarkan uraian di atas, dapat dikemukakan beberapa saran seperti berikut. Pertama, Dosen perlu menggunakan model perkuliahan yang memfasilitasi aktivitas diskusi mahasiswa. Penilaian diskusi perlu dilakukan untuk meningkatkan partisipasi dan antusiasme peserta didik dalam mengikuti proses pembelajaran. Sebagaimana dikemukakan oleh Holliday (2002) bahwa kerja kelompok dalam kelompok ahli dan kelompok jigsaw perlu dinilai untuk menjamin partisipasi semua orang. Kedua, mahasiswa perlu dimotivasi dan diberikan pemahaman yang baik dalam penerapan model jigsaw, sehingga mahasiswa benar-benar memahami manfaat berdiskusi dan penerapan model jigsaw dapat terlaksana sebagaimana mestinya.

\section{UCAPAN TERIMA KASIH}

Penelitian ini merupakan hibah Penelitian Dosen Pemula yang dibiayai oleh DIPA DP2M Kementerian Pendidikan dan Kebudayaan Tahun 2013. Oleh karena itu, Tim Peneliti mengucapkan terima kasih kepada: (1) Direktorat Jenderal Pendidikan Tinggi (Dirjen Dikti); (2) Ketua STKIP PGRI Sumatera Barat yang telah memberikan sumbangan pemikiran dan saran, UP3M STKIP PGRI Sumatera Barat dan Kopertis wilayah X; dan (3) Mitra Bestari dan Redaktur Jurnal Cakrawala Pendidikan yang banyak memberikan masukan dalam penulisan artikel ini.

\section{DAFTAR PUSTAKA}

Arends, Richard I. 2012. Learning to Teach (Ninth Edition). New York: McGrawhill. 
Chan, Kam-Wing. 2004. 'Using Jigsaw II' in teacher Education Programmes". Hong Kong Teachers' Centre Journal, 3, hlm. 91-97.

Darnon, Céline, Céline Buchs, dan Delphine Desbar. 2012. "The Jigsaw Technique and Self-Efficacy of Vocational Training Students: a Practice Report". European Journal of Psychology of Education, 27 (3), hlm.439-449.

Denton, D.W. 2012. "Enhancing Instruction through Constructivism, Cooperative Learning, and Cloud Computing". Tech Trends, 56 (4), hlm.34-41.

Ewing, Bronwyn. 2011. "Direct Instruction in Mathematics: Issues for Schools with High Indigenous Enrolments: A Literature Review". Australian Journal of Teacher Education, 36 (5), hlm.64-91.

Fries, Carmen. 2008. "Online Jigsaw Science Inquiry for Preservice Teachers". Journal of Computing in Teacher Education, 24 (3), hlm.85-92.

Hertiavi, Langlang, dan Khanafiyah. 2010. "Penerapan Model Pembelajaran Kooperatif Tipe Jigsaw untuk Peningkatan Kemampuan Pemecahan Masalah Siswa SMP”. Jurnal Pendidikan Fisika Indonesia, 6 (1), hlm.53-57.

Holliday, D.C. 2002. Jigsaw IV: Using Student/ Teacher Concerns to Improve Jigsaw III. ERIC ED 465687.

Hsiung, Chin Min. 2012. "The Effectiveness of Cooperative Learning". Journal of Engineering Education, 101 (1), hlm.119-137.

Lewis, Ramon. 2012. "The Effect of Jigsaw Learning on Students' Attitudes in a Vietnamese Higher Education Classroom". International Journal of Higher Education, 1(2), hlm.9-20.
McNamara, Judith dan Burton, Kelley. 2009. "Assessment of Online Discussion Forum for Law Students". Journal of University Teaching \& Learning Practice. http://ro.uow.edu.au/jutlp/vol6/iss2/6. Diunduh 15 April 2015.

Mengduo, Qiao dan Xiaoling, Jin. 2010. "Jigsaw Strategy as a Cooperative Learning Tech-nique: Focusing on the Language Learners". Chinese journal of Applied Linguistics (Bimonthly), 33 (4), hlm.113-125.

Naomi, Mbacho dan Githua, Bernard Nyingi. 2013. "Effect of Jigsaw Cooperative Learning Strategy on Students' Achievement in Secondary School Mathematics in Laikipia East District, Kenya". Asian Journal of Management Sciences and Education, 2(3), hlm.177-188.

Nurgiyantoro, Burhan. 2008. "Penilaian Otentik". Cakrawala Pendidikan, XXVII (3), hlm.250-261.

Nurhaeni, Yani. 2011. "Meningkatkan Pemahaman Siswa pada Konsep Listrik melalui Pembelajaran Kooperatif Tipe Jigsaw pada Siswa Kelas IX SMPN 43 Bandung". Jurnal Penelitian Pendidikan, 12 (1), hlm.77-89.

Saguni, Fatimah. 2013. "Efektivitas Metode Problem Based Learning, Cooperative Learning Tipe Jigsaw, dan Ceramah sebagai Problem Solving dalam Mata Kuliah Perencanaan Pembelajaran". $\mathrm{Ca}$ krawala Pendidikan, XXXII (2), hlm. 207-219.

Sharan, Shlomo. 1999. Handbook of Cooperative Learning. Terjemahan oleh Sigit Prawoto. 2012. Yogyakarta: Familia.

Sukarta, I Nyoman dan I Made Gunamantha. 2012. "Pembelajaran Kooperatif Tipe Jigsaw dalam Mata Kuliah Teknologi Air 
dan Pengolahan Limbah Industri”. $\mathrm{Ca}$ krawala Pendidikan, XXXI (1), hlm.129142.

Suryabrata, Sumadi. 2004. Metodologi Penelitian. Jakarta: PT. Raja Grafindo Persada.

Turaçoğlu, Alpat, dan Ellez. 2013. "Effects of Jigsaw on Teaching Chemical Nomen- clature". Education and Science, 38 (167), hlm.256-272.

Wijaya, Anggita Langgeng. 2012. "Pengaruh Tingkat Partisipasi Kelas terhadap Kinerja Akademik Mahasiswa". Jurnal Ekonomi \& Pendidikan, 9 (1), hlm.124-132. 